\title{
Differenz
}

Revista internacional de estudios heideggerianos y sus derivas contemporáneas

AÑO 2 NÚMERO 1: JULIO DE 2015. e-ISSN: 2386-4877 - DOI: 10.12795/DIFFERENZ.2015.I01.07

[pp.103-121]

Recibido: 02/06/2015

Aceptado: 20/06/2015

\section{Variaciones excepcionalistas: Heidegger, lo político, hoy.}

\section{Exceptionalist Variations: Heidegger, the Political, Today}

\section{Facundo Vega}

Cornell University-Humbold-Universität zu Berlin-Universidad de Buenos Aires

\section{Resumen:}

La tematización que Martin Heidegger realizó sobre la noción de "lo político" fue siempre subsidiaria respecto de la primacía que el autor de Sein und Zeit le asignó a la noción de ró̀ıs, entendida como el sitio esencial en el que la historia se despliega. Contra Heidegger, sin embargo, la referencia a "lo político" se multiplica en la filosofía política contemporánea. En años recientes, de hecho, un "giro ontológico" en esta disciplina ha proclamado una distinción analítica entre "la política" -ámbito referido a las prácticas y expresiones empíricas de las relaciones de poder y toma de decisiones- y "lo político" -es decir, el modo en el que la sociedad es instituida. Paradójicamente, Heidegger fue entendido como el precursor teórico de esta maniobra, también denominada "diferencia política". Esta problemática re-apropriación de la "diferencia ontológica" heideggeriana indica que "la política" refiere al nivel de los entes, mientras que "lo político" tiene estricta relación con el ámbito del ser. Poniendo atención en la reflexión heideggeriana sobre das Politische, sin embargo, el presente texto problematiza esta re-apropiación 
contemporánea, considerando el problema teórico que está a la base de la transpolación de la ontología fundamental al ámbito de la política. En particular, se buscará mostrar la manera en la que Heidegger lidió con lo que puede ser entendido como una "fascinación por lo extra-ordinario", impugnando la omnipresencia de "lo político". Una interrogación guiará nuestra examinación, a saber: ¿Heidegger sucumbió ante esta fascinación? 0 más apropiadamente, ¿su obra resulta aprisionada entre la crítica a la imposición del esencialismo metafísico en la modernidad y una "fascinación por lo extraordinario" tal como la que es asumida inexaminadamente en el elogio contemporáneo de "lo político"?

Palabras Clave: política, "lo político", ordinario, extraordinario, excepcionalismo

\section{Abstract:}

Martin Heidegger's thematization of the notion of das Politische was always secondary to the primacy he assigned to the notion of ró $\lambda$ ıs, understood as the essential site of history's unfolding. In contrast to Heidegger, reference to das Politische is becoming more prevalent in contemporary political philosophy. In recent years, in fact, an "ontological turn" in political philosophy has claimed an analytical distinction between "politics" which refers to the manifold practices and empirical expressions of power relations and decision-making - and "the political" - understood as the way in which society is instituted. Paradoxically, however, several authors have traced Heidegger's notion of "ontological difference" as precursory to this theoretical maneuver called "political difference." This questionable re-appropriation of "ontological difference" assumes that "politics" refers to the level of beings, while "the political" strictly relates to the realm of being. Focusing on Heidegger's considerations on das Politische, my paper will problematize this contemporary re-appropriation by emphasizing the theoretical problem inherent to the extrapolation of politics from ontology. In particular, I will attempt to show how Heidegger dealt with what can be understood as a "fascination with the extraordinary" by rejecting the omnipresence of das Politische. The main question that guides my entire examination is whether Heidegger succumbed to this fascination. Or, more specifically, is Heidegger's work confined by his critique of the imposition of metaphysical essentialism in modernity and a "fascination with the extraordinary" that contemporary re-appropriations simply overlook in their adoption of "the political"?

Keywords: politics, "the political", ordinary, extraordinary, exceptionalism 
Cuán común y pequeño es este domingo en la ciudad; la peculiar mezcla de esto común y pequeño sólo puede ser efectivamente expresada a través de la palabra extranjera "ordinär"

\section{Martin Heidegger, Schwarze Hefte}

¿Cómo vivir en común luego de que la fe en el fundamento trascendente que solía ordenar los lazos políticos cayó en desgracia? ¿Es posible fundar un "nuevo entramado de significaciones políticas" sobre un abismo? O puesto de manera distinta, aquellos que intentamos reflexionar sobre la política, ¿estamos compelidos a completar ese vacío o debemos proteger su vacuidad? El tono de estas interrogaciones expresa, quizás toscamente, cierta reluctancia respecto de las asunciones políticas tradicionales que indicaban la primacía de un polo unívoco e incondicionado como último cimiento de la vida en común. La remisión a la tradición, se sostiene generalmente, es fútil cuando se trata de lidiar con la novedad de un mundo que ya no es sostenido por valores esenciales y extra-naturales. ${ }^{1}$ Nuestra propia actualidad, de hecho, muestra cómo una miríada de obras críticas respecto de la tradición metafísica se ha generalizado. ${ }^{2}$

Llamativamente, sin embargo, un nuevo tono esencialista se expande dentro de las tendencias en boga en la filosofía política: la "fascinación por lo extraordinario". Mi disertación, Extraordinary Matters: Politics and Being-in-Common after Martin Heidegger, cuestiona lo que he denominado "excepcionalismo" ${ }^{3}$, es decir, la invocación de

1 Este específico gesto crítico frente a la persistencia de lo establecido es evidente, por caso, cuando Hannah Arendt reivindica un «pensar sin barandilla» o cita el verso de René Char que sugiere que "Nuestra herencia nos fue legada sin testamento alguno.» ARENDT, H.: "Hannah Arendt: On Hannah Arendt", en HILL, M.: Hannah Arendt. The Recovery of the Public World. New York: St. Martin's Press, 1979, pp. 336-337; Between Past and Future: Eight Exercises in Political Thought. New York: Penguin Books, 1993, p. 3; y On Revolution. New York: Penguin Books, 2006, p. 207. La diatriba con respecto a la mera repetición de la tradición y de los absolutos metafísicos es también conspicua cuando, al estudiar la obra de Maurice Merleau-Ponty, Claude Lefort refiere a la «columna ausente» de Henri Michaux o cuando establece, en una cita por demás revisitada, que «la democracia se instituye y se mantiene en la disolución de los referentes de la certeza." LEFORT, C. : Sur une colonne absente: écrits autour de Merleau-Ponty. París : Éditions Gallimard, 1978; y Essais sur le politique. XIXe - XXe siècles. París: Éditions du Seuil, 1986, p. 29. Énfasis en el original.

2 Ver, entre otras obras: DERRIDA, J.: L'Écriture et la différence. Paris: Éditions du Seuil, 1967; LACLAU, E.: Emancipation(s). London: Verso, 1996; LEFORT, C.: L'Invention démocratique. París: Fayard, 1981 y Essais sur le politique. XIXe - XXe siècles; RORTY, R.: Contingency, Irony, and Solidarity. Cambridge: Cambridge University Press, 1989.

3 Como resultará claro, al hablar sobre "excepcionalismo", no me refiero en modo alguno a interpretaciones problemáticas tales como las mentadas en: WolIN, R.: Heidegger's Children. 
acontecimientos políticos inusuales como la clave de bóveda y el horizonte último a través de los cuales la vida cotidiana (pero no sólo la vida cotidiana) puede ser aprehendida. En esta intervención analizaré particularmente una instanciación significativa de la "fascinación por lo extraordinario", a saber, aquella entrañada por el afán en transpolar la ontología, en tanto pregunta por el ser, al territorio político. El ser de la política, se sugiere sin cesar, es el conflicto y la contingencia. En años recientes y como consecuencia de un "giro ontológico" en la filosofía política, se ha proclamado una distinción analítica entre "la política" - ámbito referido a las prácticas y expresiones empíricas de las relaciones de poder- y "lo político" - es decir, el modo en el que la sociedad es instituida. Paradójicamente, Martin Heidegger fue entendido como el precursor teórico de esta maniobra, también denominada "diferencia política". ${ }^{4}$ Esta problemática re-apropriación de la "diferencia ontológica" heideggeriana indica que "la política" refiere al nivel de los entes, mientras que "lo político" tiene estricta relación con el ámbito del ser. Sin embargo, en mayor medida, Heidegger impugnó la noción de "lo político" (das Politische), declarándola subsidiaria de la de $\pi o ́ \lambda ı \varsigma$, es decir, del sitio esencial en el que la historia se despliega.

Con el objeto de escrutar estos problemas teóricos, en la primera sección del texto se buscará mostrar cómo la entronización del autor de Sein und Zeit en el pensador de "lo político" supone una malcomprensión de la filosofía heideggeriana. Es precisamente la remisión a "lo político" aquella que, se afirma de manera peculiar, muestra el antiesencialismo heideggeriano, su carácter deconstructivo respecto de la tradición y la potencialidad de su pensamiento para la radicalización democrática. Sin embargo, tal como se intentará dejar en claro, Heidegger considera la referencia a "lo político"

Hannah Arendt, Karl Löwith, Hans Jonas, and Herbert Marcuse. Princeton: Princeton University Press, 2001: p. 63.

4 MArChart, O.: Post-Foundational Political Thought: Political Difference in Nancy, Lefort, Badiou and Laclau. Edinburgh: Edinburgh University Press, 2007; Die politische Differenz. Zum Denken des Politischen bei Nancy, Lefort, Badiou, Laclau und Agamben. Berlín: Suhrkamp Verlag, 2010. Si bien una extensa variedad de autores tales como Friedrich Schiller, Friedrich Schlegel, Georg Jellinek, Max Weber, Carl Schmitt, Helmuth Plessner, Julien Freund o Paul Ricœur, entre otros, contribuyeron a la emergencia de esta tematización, sólo recientemente esta "diferenciación lingüística se ha convertido en una distinción semántica.» VOLLRATH, E.: "The 'Rational' and the 'Political': An Essay in the Semantics of Politics" en Philosophy and Social Criticism 13, 1987, p. 19. Ver, también: PALONEN, K.: "Politics or the political? An historical perspective on a contemporary non-debate" en European Political Science 6, 2007, pp. 69-78; vollRATH, E.: "The 'Rational' and the 'Political': An Essay in the Semantics of Politics" en Philosophy and Social Criticism 13, 1987, p. 20; "Politisch, das Politische", en RITTER, J. Y GRÜNDER, K.: Wörterbuch der Philosophie: Historisches Band 7. Basel: Wissenschaftliche Buchgesellschaft, 1989, pp. 1071-1075; BEDORF, T. y RÖTTGERS, K. (ed.): Das Politische und die Politik. Berlín: Suhrkamp Verlag, 2010; BRÖCKLING, U. y FEUSTEL, R. (ed.): Das Politische denken. Zeitgenössische Positionen. Bielefeld: Transcript, 2010. 
justamente como la expresión par excellence del esencialismo propio de la metafísica tradicional. En el segundo apartado de este ensayo, entonces, se analizará la manera en la que Heidegger impugna la noción de "lo político". La elucidación heideggeriana sobre "lo político", buscará establecerse, escenifica la elucidación del entrelazamiento entre momentos "ordinarios" y "extraordinarios" que atraviesa buena parte de la obra del pensador pero que, en este caso, tiene como contraparte crítica las consideraciones de Carl Schmitt sobre el asunto.

1. Frente al impasse del consensualismo político, diversas obras filosóficas y teóricopolíticas reivindicaron el carácter contencioso de la vida en común. ${ }^{5}$ La consideración de nociones tales como "conflicto" y "contingencia" buscaba poner a la luz el carácter mutable propio de las acciones políticas y expresaba una impugnación de gran fuerza intelectual frente al estancamiento analítico de las filosofías políticas del progreso y el determinismo economicista. O, para expresarlo de un modo ligeramente diferente, la impugnación al consensualismo y la concomitante reivindicación de la división social como suelo de la política, resultaron invectivas de gran vigor frente a perspectivas tradicionales poco fructíferas para comprender la novedad de un mundo político que ya no podía sostenerse en la invocación a fundamentos absolutos. Es bajo esa luz que, propongo, deben ser leídas las referencias a la obra de Heidegger por parte de autores que buscaron tematizar "lo político" como expresión del "conflicto" y la estructural contingencia.

A pesar de que la obra heideggeriana no resulta, stricto sensu, una elaboración en el ámbito propio de la filosofía política, ${ }^{6}$ con remarcable agudeza intelectual se señaló su

\footnotetext{
5 Ver, entre otros trabajos: AgAmBEn, G., et al.: Démocratie, dans quel état? París: La Fabrique, 2009; BADIOU, Alain, Peut-on penser la politique?, París, Éditions du Seuil, 1985; BALIBAR, É.: La crainte des masses. Politique et philosophie avant et après Marx. París: Éditions Galilée, 1997; LACLAU, E. Y MOUfFE, C.: Hegemony and Socialist Strategy: Towards a Radical Democratic Politics. London: Verso, 2001; LEFORT, C.: Essais sur le politique. XIXe - XXe siècles; RANCIÈRE, J.: La mésentente. Politique et philosophie. París: Éditions Galilée, 1995.

6 Sin embargo, existe una variedad innúmera de estudios en los que se asocia la filosofía heideggeriana a temas políticos. Ver, entre otras obras: LöWITH, K.: Heidegger: Denker in Dürftiger Zeit. Frankfurt am Main: Fischer, 1953; LUKÁcs, G.: Die Zerstörung der Vernunft. Der Weg des Irrationalismus von Schelling zu Hitler. Berlin (Ost): Aufbau-Verlag, 1954; STRAUSS, L.: Natural Right and History. Chicago: The University of Chicago Press, 1953; Studies in Platonic Political Philosophy, (Thomas Pangle ed.). Chicago/Londres: The University of Chicago Press, 1983; The Rebirth of Classical Political Rationalism, (Thomas Pangle ed.). Chicago: The University of Chicago Press, 1989; VON KROCKOW, C.: Die Entscheidung: Eine Untersuchung über Ernst Jünger, Carl Schmitt, Martin Heidegger. Stuttgart: F. Enke, 1958; SCHNeEberGer, G.: Nachlese zu Heidegger: Dokumente zu seinem Leben und Denken. Berna: Selbstverlag, 1962; Adorno, T.: Jargon der Eigentlichkeit. Zur deutschen Ideologie, en Gesammelte Schriften Band 6. Frankfurt: Suhrkamp Verlag, 1997; Schwan,
} 
A.: Politische Philosophie im Denken Heideggers. Oplanden: Westdeutscher Verlag, 1965; PALMIER, J.: Les écrits politiques de Heidegger. París: L'Herne, 1968; BOURDIEU, P.: L'Ontologie politique de Martin Heidegger. París: Les Éditions de Minuit, 1988; PÖGGELER, O.: Philosophie und Politik bei Heidegger. Freiburg, München: Verlag Karl Alber, 1972; MARCUSE, H.: "Heidegger's Politics: An Interview" en Graduate Faculty Philosophy Journal VI, № 1, 1977, pp. 28-40; HABERMAS, J.: "Martin Heidegger", en Philosophisch-politische Profile. Frankfurt am Main: Suhrkamp Verlag, 1971, pp. 67-92; SCHÜRMANN, R.: "Political Thinking in Heidegger" en Social Research 45, № 1, Spring, 1978, pp. 191-221; HARRIES, K.: "Heidegger as a Political Thinker", en MURRAY, M.: Heidegger and Modern Philosophy. Critical Essays, New Haven: Yale University Press, 1978, pp. 304-328; Le principe d'anarchie. Heidegger et la question de l'agir. París: Éditions du Seuil, 1982; BLITZ, M.; Heidegger's Being and Time and the Possibility of Political Philosophy. Ithaca: Cornell University Press, 1981; NEWELL, W.: "Heidegger on Freedom and Community: Some Implications of His Early Thought" en American Political Science Review 78, № 3, 1984, pp. 775-784; NANCY, J.: La communauté désceuvrée. París: Christian Bourgois, 1986; Être singulier pluriel. París: Éditions Galilée, 1996 ; FARíAS, V.: Heidegger et le nazisme. París: Verdier, 1987; LACOUE-LABARTHE, P.: La fiction du politique. Heidegger, l'art et la politique. París: Christian Bourgois Éditeur, 1987; SHEEHAN, T.: "Heidegger and the Nazis" en The New York Review of Books XXXV, № 10, 16 de Junio, 1988, pp. 38-47; FERRY, L. y RENAUT, A.: Heidegger et les Modernes. París: Grasset, 1988; GeThMANN-SIEFERT, A. y PÖGGeLER, O. (ed.): Heidegger und die praktische Philosophie. Frankfurt am Main: Suhrkamp Verlag, 1989; ZUCKERT, C.: "Martin Heidegger: His Philosophy and His Politics" en Political Theory 18, 1990, pp. 51-79; JANICAUD, D.: L'ombre de cette pensé. Heidegger et la question politique. Grenoble: Éditions Jérôme Million, 1990; woulN, R.: The Politics of Being: The Political Thought of Martin Heidegger. New York: Columbia University Press, 1990; LOSURDO, D.: La comunità, la morte, l'Occidente. Heidegger e l' 'ideologia della guerra'. Torino: Bollati Boringhieri editore, 1991; ADLER, P., et al.: "A Chronological Bibliography of Heidegger and the Political" en Graduate Faculty Philosophy Journal 14, № 2 - 15 № 1, 1991, pp. 581-611; ROCKMORE, T.: On Heidegger's Nazism and Philosophy. Berkeley: University of California Press, 1992; DERRIDA, J.: Politiques de l'amitié. París: Éditions Galilée, 1994; SLUGA, H.: Heidegger's Crisis: Philosophy and Politics in Nazi Germany. Cambridge: Harvard University Press, 1995; HeLD, K.: "Authentic Existence and the Political World" en Research in Phenomenology 26, 1996, pp. 38-53; VILLA, D.: Arendt and Heidegger. The Fate of the Political. Princeton: Princeton University Press, 1996; ESPOSITO, R.: Communitas. Origine e destino della comunità. Torino: Giulio Einaudi, 1998; FRITSCHE, J.: Historical Destiny and National Socialism in Heidegger's Being and Time. Berkeley y Los Angeles: University of California Press, 1999; FRIED, G.: Heidegger's Polemos. From Being to Politics. New Haven: Yale University Press, 2000; KISIEL, T.: "Heidegger als politischer Erzieher: Der NS-Arbeiterstaat als Erziehungsstaat: 1933-1934", en LEŚNIEWSKI, N. y NOWAK-JUCHACZ, E.: Die Zeit Heideggers, Band 2. Frankfurt am Main: Peter Lang, 2002, pp. 71-87; "Political Interventions in the Lecture Courses of 1933-36", en DENKER, A. y ZABOROWSKI, H.: Heidegger und der Nationalsozialismus II. Interpretationen. Freiburg/München: Karl Alber, 2009, 110-129; FAYE, E.: Heidegger, l'introduction du nazisme dans la philosophie. París: Éditions Albin Michel, 2005; RADLOFF, B.: Heidegger and the Question of National Socialism. Disclosure and Gestalt. Toronto: Toronto University Press, 2007; MARCHART, O.: Post-Foundational Political Thought: Political Difference in Nancy, Lefort, Badiou and Laclau; Die politische Differenz. Zum Denken des Politischen bei Nancy, Lefort, Badiou, Laclau und Agamben; GROSSER, F.: Revolution denken. Heidegger und das Politische 1919-1969. München: C. H. Beck Verlag, 2011.

7 Ver, entre otros trabajos: BIRMIngham, P.: "The Time of the Political" en Graduate Faculty Philosophy Journal 14, № 2- 15, №1, 1991, pp. 25-45; de BEISTEGUI, M.: Heidegger and the political. Dystopias. New York: Routledge, 1998; LACOUE-LABARTHE, P.: La fiction du politique. Heidegger, l'art et la politique; SCHÜRMAN, R.: Le principe d'anarchie. Heidegger et la question de l'agir. 
llamativa inversión de la postura heideggeriana sobre este término, diversos autores han tomado el pensamiento del filósofo como antecedente para mentar una distinción analítica denominada "diferencia política". ${ }^{8}$ Chantal Mouffe, por caso, refiere a esta diferenciación teórica y sostiene que «si queremos expresar tal distinción de manera filosófica, podemos decir, adoptando el vocabulario de Heidegger, que la política refiere al nivel 'óntico' mientras que 'lo político' tiene relación con el nivel 'ontológico'.» Y luego, Mouffe agrega que «lo óntico se remite a las múltiples prácticas de la política convencional, mientras que lo ontológico refiere al modo en el que la sociedad es instituida. ${ }^{9}$ La posición de Fred Dallmayr expresa un sesgo similar al afirmar que la distinción entre "la política" y "lo político" "se relaciona oblicuamente con la noción de diferencia óntico-ontológica heideggeriana. ${ }^{10}$ Sobre la base de este tipo de aseveraciones se erige la "diferencia política": mientras "la política" refiere al ámbito concreto de la toma de decisiones, "lo político" está enlazado a la esfera desde la cual la política emerge.

Definida por su talante crítico, esta forma intelectual implica una filosofía política postfundacionalista, basada en la centralidad de las nociones de contingencia y antagonismo, que busca el debilitamiento ontológico de los fundamentos políticos. Un dictum tal como «el fundamento funda en tanto abismo $»^{11}$, por caso, prefiguraría la operación de

8 Ver: Mouffe, C.: The Return of the Political. London, New York: Verso, 1993; On the Political. London and New York: Routledge, 2005; MARCHART, O.: Post-Foundational Political Thought: Political Difference in Nancy, Lefort, Badiou and Laclau; Die politische Differenz. Zum Denken des Politischen bei Nancy, Lefort, Badiou, Laclau und Agamben. Sobre esta distinción, ver también: BosTEELS, B.: The Actuality of Communism. London: Verso, 2011, pp. 65-69.

9 Mouffe, C.: On the Political, pp. 8-9. Me he dedicado en un sentido general a este tópico en: Vega, F. et. al.: "Contours of Marxism" en The Institute of Comparative Modernities Newsletter 4, Ithaca, Cornell University, 2012, pp. 23-24.

10 DallmaYr, F.: The Other Heidegger. Ithaca: Cornell University Press, 1993, p. 51. Ver también: DallmaYr, F.: The Other Heidegger, p. 76; DAllmaYR, F.: Polis and Praxis. Exercises in Contemporary Political Theory. Cambridge, Massachusetts: The MIT Press, 1984, p. 106; WolIN, S.: Politics and Vision. Continuity and Innovation in Western Political Thought. Boston: Little, Brown and Company, 1960, p. 43; SCHMITT, C.: Der Begriff des Politischen. Berlín: Duncker \& Humblot, 1963; RICCEUR, P.: “Le Paradoxe Politique", en Histoire et Vérité. París: Éditions du Seuil, 1964, pp. 260-284; PITKIN, Hanna, 1972, Wittgenstein and Justice, Berkeley, University of California Press, p. 215; LACOUE-LABARTHE, P. y NANCY, J. (ed.): Rejouer le Politique. París: Éditions Galilee, 1981; VOLLRATH, E.: Grundlegung einer philosophischen. Theorie des Politischen. Würzburg: Königshausen \& Neumann, 1987 A, pp. 29-56; VollRath, E.: "The 'Rational' and the 'Political': An Essay in the Semantics of Politics", pp. 17-29; Was ist das Politische? Eine Theorie des Politischen und seiner Wahrnehmung. Würzburg: Königshausen \& Neumann, 2003, pp. 75-97; BOLSINGER, E. The Autonomy of the Political. Carl Schmitt's and Lenin's Political Realism. Westport: Greenwood Press, 2001; GEUSS, R.: Philosophy and Real Politics. Princeton: Princeton University Press, 2008.

11 HeIdegger, M.: Beiträge zur Philosophie (Vom Ereignis), (Friedrich von Hermann ed.), Gesamtausgabe, Band 65. Frankfurt am Main: Vittorio Klostermann, 1994, p. 29. 
esta corriente teórica. Bajo, entre otros, este impulso, sus animadores sostienen que es indudable que la filosofía heideggeriana ocupa un rol eminente para el pensamiento crítico. Sin embargo, la interpretación que propone la presente intervención difiere acerca de "cuál" Heidegger es el que influencia la teoría crítica contemporánea. En buena medida, lo que permanece en las vertientes que bregan por un "recentramiento de lo político" es cierta "fascinación por lo extraordinario". Puesto de modo diferente, las perspectivas teóricas que entronizan la noción de "lo político" extraen de ella la vitalidad requerida por un mundo político abierto al antagonismo y la contingencia. Pero, intentamos preguntar, ¿a qué precio ${ }^{12}$

Es en el prefacio de uno de los más prominentes intentos por señalar cómo la división social está a la base de la política donde podemos leer que «lo político (the political) [se concibe...] como [...] poseyendo el status de una ontología de lo social. Desde este argumento se sigue que [...] la división social es inherente a la posibilidad de la política.» ${ }^{13}$ Una política radical, se estima, requiere la aceptación de la inerradicabilidad del antagonismo. Así, la reivindicación del carácter conflictivo y contingente de la política, es erigida como forma de aproximación anti-esencialista, motivo que acercaría el proyecto de reflexión sobre una política radical a uno de los motivos distinguidos de la filosofía heideggeriana. De hecho, Ernesto Laclau especificó que puesto que «por razones esenciales [...] la plenitud de la sociedad es inalcanzable, esta ruptura en la identidad de los agentes políticos es una 'diferencia ontológica' - en un sentido no enteramente escindido del uso que Heidegger hizo de esta expresión- absolutamente constitutiva.» ${ }^{14}$ Lo que se busca enfatizar, de cualquier modo, es la necesidad de detectar el gesto "excepcionalista" inherente en esta maniobra teórica y las implicaciones que puede tener para un proyecto filosófico-político de estro anti-esencialista. Puesto de manera concisa, la invocación de la democracia como un orden radical y remiso a los fundamentos esenciales no puede reproducir una "diferencia política" que restituya el binarismo que distingue de modo

12 Agradezco especialmente a Jean-Luc Nancy por el diálogo que hemos mantenido sobre las repercusiones de la distinción entre "la política" y "lo político" en febrero de 2015 en Strasbourg.

13 LACLAU, E. y MOUfFE, C.: Hegemony and Socialist Strategy: Towards a Radical Democratic Politics, p. XIV. (Énfasis en el original).

14 LACLAU, E.: Emancipation(s). London: Verso, 1996, pp. 60-61. (Énfasis agregado). Ver también: LACLAU, E. y ZACK, L.: "Minding the Gap: The Subject of Politics", en LACLAU, E.: The Making of Political Identities. London and New York: Verso, 1994, pp. 11-39; y MARCHART, O.: "Politics and the Ontological Difference. On the 'Strictly Philosophical' in Laclau's Work", en MARCHART, O. y CRITCHLEY, S.: Laclau: A Critical Reader, London y New York, Routledge, 2004, pp. 54-72. En contadas pero valiosas oportunidades pude discutir acerca del vínculo entre la "diferencia política" y el pensamiento heideggeriano con Ernesto Laclau. Frente a la pérdida, quizás convenga recordar que Denken ist Danken. 
tajante entre lo políticamente "ordinario" y "extraordinario". ${ }^{15} \mathrm{Y}$, más especialmente en lo atinente a este ensayo, resulta imperativo interrogar: ¿puede la filosofía heideggeriana ser el connubio teórico de esta entronización de "lo político"? En un momento en el que la "diferencia política" goza de buena salud, y el "elogio de lo político" aprisiona la sorpresa que anima la política, esta es, creo, una de las tareas filosófico-políticas que debemos afrontar.

2. Si bien la exégesis de la obra heideggeriana como fuente nutricia para desplegar la "diferencia política" data de años recientes, la consideración acerca de "lo político" como ámbito esencial y sino de la vida en común no reviste signos de novedad. Fue, sin dudas, Der Begriff des Politischen, publicado en su primera versión en 1927, el texto señero que instituyó el inicio de una tematización cuya generalización hoy es conspicua. Pero el libro de Schmitt, a la vez, tiene un carácter esencial respecto de aquello que motiva esta intervención, a saber, problematizar el modo en el que, contemporáneamente, se sugiere que la obra de Heidegger hace las veces de precursora del "elogio de lo político". La idea que defiende la presente interpretación, puesta concisamente, es que Heidegger fue un crítico virulento de la noción de "lo político" y ello sólo puede aprehenderse si se toma en consideración su conocimiento de la segunda edición de Der Begriff des Politischen, tal como resulta ostensible en la única carta - al menos en los registros con los que actualmente se cuenta- que el filósofo le hizo llegar a Schmitt. ${ }^{16}$ No es, por caso, en Sein

15 Esta deriva es una de las particularidades del "elogio de lo político" en clave populista. En la obra más destacada que se haya escrito sobre este asunto, se sugiere que el populismo es «un modo de construir lo político» que se distingue nítidamente respecto de la política institucional y su énfasis en el administrativismo gradualista. LACLAU, E.: On Populist Reason. London: New York, Verso, 2005 p. XI. (Énfasis agregado). En contraposición, sugiere On Populist Reason, la política administrativa corporiza el mito de la «sociedad totalmente reconciliada - lo cual presupone invariablemente la ausencia de un liderazgo, es decir, el desvanecimiento de lo político." LACLAU, E.: On Populist Reason, pp. 61-62. (Énfasis en el original en primer lugar, y agregado, luego). Resulta imposible analizar de forma acendrada las implicancias de esta sofisticada mixtura de invocaciones ontológicas - que, es conveniente recordarlo, se quieren de algún modo legatarias del pensamiento heideggeriano- y asunciones filosófico-políticas en este breve texto, incluso cuando en On Populist Reason se estima que «el populismo es la vía regia para comprender algo acerca de la constitución ontológica de lo político en tanto tal.» LACLAU, E.: On Populist Reason, p. 67. (Énfasis agregado).

16 HEIDEGGER, M.: Reden und andere Zeugnisse eines Lebensweges 1910-1976, (Hermann Heidegger ed.), Gesamtausgabe, Band 16. Frankfurt am Main: Vittorio Klostermann, 2000, p. 156. Agradezco los breves comentarios de Arnulf Heidegger y Peter Trawny sobre este asunto. Heinrich Meier observa que, erróneamente, diversos historiadores y periodistas han comentado sobre la existencia de otra carta fechada el 22 de abril de 1933 en la que Heidegger invita a Schmitt a formar parte del partido Nacionalsocialista, MEIER, H.: Die Lehre Carl Schmitts: Vier Kapitel zur Unterscheidung Politischer Theologie und Politischer Philosophie. Stuttgart: J. B. Metzler Verlag und Carl Ernst Poeschel Verlag, 1994. Ver también: OTT, H.: Martin Heidegger. Unterwegs zu seiner Biographie. Frankfurt am Main: 
und Zeit, obra también publicada en el año 1927, donde pueden leerse las invectivas de Heidegger sobre "lo político". ${ }^{17}$ El tono de exaltada ofuscación respecto de esta noción se tornará palpable, en cambio, en los seminarios que Heidegger impartió luego del intercambio epistolar con Schmitt. Veamos cómo se expresa su posición.

No hay dudas de que el pensamiento heideggeriano está animado por un radicalismo filosófico que roza la "fascinación por lo extraordinario". ${ }^{18}$ Esto es patente, por caso, en

Campus Verlag, 1988, p. 226; ROTHER, R.: Wie die Entscheidung lesen? Zu Platon, Heidegger, und Carl Schmitt. Wien: Turia \& Kant, 1993, pp. 67-75, 237; FRIED, G.: Heidegger's Polemos. From Being to Politics, p. 28; WAITE, G.: "Heidegger, Schmitt, Strauss: The Hidden Monologue, or, Conserving Esotericism to Justify the High Hand of Violence" en Cultural Critique 69, Spring, 2008, pp. 122123. Por lo tanto, de acuerdo a Meier, pareceres acerca de la existencia de esta carta como los de Joseph Bendersky, Víctor Farías, Gopal Balakrishnan, Jan-Werner Müller, o Jeffrey Robbins, están fundados en una equivocación. Ver: BENDERSKY, J.: Carl Schmitt. Theorist for the Reich. Princeton: Princeton University Press, 1983, p. 203; FARÍAS, V.: Heidegger et le nazisme, p. 151; BALAKRISHNAN, G.: The Enemy. An Intellectual Portrait of Carl Schmitt. London: Verso, 2000, p. 181; MüLLER, J.: A Dangerous Mind. Carl Schmitt in Post-War European Thought. New Haven: Yale University Press, 2003, p. 37; RoBBINS, J.: Radical Democracy and Political Theology. New York: Columbia University Press, 2011, p. 13. Nada de esto aliviana el hecho de que ambos, Heidegger y Schmitt, mantuvieron un compromiso totalitario que puede ser leído como la expresión más ominosa de la tentación "excepcionalista".

17 En su magnum opus, de hecho, sólo existen dos menciones al término "política", la primera en tanto sustantivo, la segunda en tanto adjetivo; y una referencia, simplemente incidental, al término "lo político". HeIdegGer, M.: Sein und Zeit. Tübingen: Max Niemeyer, 1967, pp. 16, 193, 400.

18 Ver, entre otros: ARENDT, H.: "What is Existenz Philosophy?" en Partisan Review XIII, № 1, Winter, 1946, pp. 34-56; ARENDT, H.: "Heidegger the Fox", en KOHN, J.: Essays in Understanding, 1930-1954. New York: Harcourt Brace, 1994, pp. 361-362; STRAUSS, L.: Natural Right and History; Spinoza's Critique of Religion. New York: Schocken Books, 1965; "An Unspoken Prologue to a Public Lecture at Saint John's [In Honor of Jacob Klein, 1899-1978]" en Interpretation 7, September, 1978, pp. 1-3; Studies in Platonic Political Philosophy; STRAUSS, L.: On Tyranny, (Victor Gourevitch y Michael S. Roth ed.). New York: The Free Press, 1991; STRAUSS, L.: “German Nihilism, Leo Strauss", en Interpretation 26 (David Janssens and Daniel Tanguay, ed.), 1999, pp. 353-78. Revisado en: Interpretation 26, 2000, pp. 33-34; BOURDIEU, P.: L'Ontologie politique de Martin Heidegger, p. 16; LOSURDO, D.: La comunità, la morte, l'Occidente. Heidegger e l' 'ideologia della guerra'; ROSEN, S.: The Elusiveness of the Ordinary. Studies in the Possibility of Philosophy. New Haven: Yale University Press, 2002; GUMBRECHT, H.: "Stichwort: Tod im Kontext Heideggers Umgang mit einer Faszination der 1920er Jahre", en Heidegger Handbuch. Stuttgart-Weimar: J. B. Metzler Verlag, 2003, pp. 98-103; Sheehan, T.: "Introduction: Heidegger, the Project and the Fulfillment", en SHEEHAN, T.: Heidegger. The Man and the Thinker. New Brunswick: Transaction Publishers, 2010, p. xvi. Me permito también reenviar a: VEGA, F.: “'Dios es muerte'. El imprudente Martin Heidegger bajo la mirada de Leo Strauss”, en CROCE, S. y BISET, E.: Exceso y prudencia, Cuadernos de Nombres. Córdoba: Editorial Brujas, 2009, pp. 139-150; "¿Es la angustia un temple de ánimo marcial? Heidegger y la ideología de la guerra" en Sin Fundamento. Revista Colombiana de Filosofía 9, Bogotá, pp. 21-47, 2009. El radicalismo heideggeriano es ostensible, a la vez, en las reflexiones sobre la metapolítica y las derivas modernas de "lo político" y la "cultura", presentes en los controversiales Schwarze Hefte: HEIDEGGER, M.: Überlegungen II-IV (Schwarze Hefte 1931 - 1938), (Peter Trawny ed.), Gesamtausgabe, Band 94. Frankfurt am Main, Vittorio Klostermann, 2014, pp. 58-59, 115-116, 499-502, 509-510; Überlegungen 


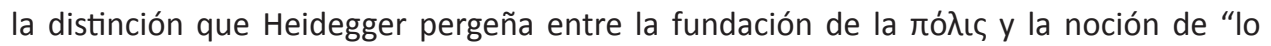
político". ${ }^{19} \mathrm{El}$ primer término, de acuerdo al pensador, se refiere al sitio esencial de la

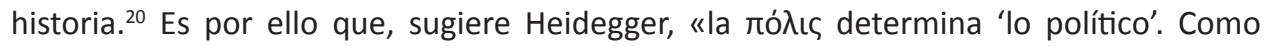
consecuencia, 'lo político' nunca puede decidir sobre su fundamento, es decir, la ró en sí misma, ni sobre su fundación. ${ }^{21}$ Podría ser argüido que la concepción de politicidad inherente a las reflexiones heideggerianas implica una confrontación contra la repetición de la "normalidad de la vida normal". ${ }^{22}$ Y, más aún, sería dable sugerir que la consideración que hace Heidegger sobre la ró $\lambda$ ıs en tanto sitio allende lo ordinario sucumbe ante los encantos del esencialismo. Pero, tal como Otto Pöggeler interroga, ¿no es la remisión a la

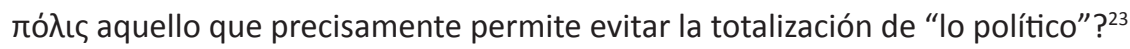

VII-XI (Schwarze Hefte 1938/1939), (Peter Trawny ed.), Gesamtausgabe, Band 95. Frankfurt am Main: Vittorio Klostermann, 2014, pp. 3-7, 12-14, 70, 112-116, 248, 303, 322-326, 334; Überlegungen XIIXV (Schwarze Hefte 1939-1941), (Peter Trawny ed.), Gesamtausgabe, Band 96. Frankfurt am Main: Vittorio Klostermann, 2014, pp. 226-228; Anmerkungen I-V (Schwarze Hefte 1942 - 1948), (Peter Trawny ed.), Gesamtausgabe, Band 97. Frankfurt am Main, Vittorio Klostermann, 2015, pp. 130131, 173, 437-438. Ver, también: Di Cesare, D.: Heidegger e gli ebrei. I "Quaderni neri". Torino, Bollati Boringhieri, 2014; Trawny, P.: Heidegger und der Mythos der jüdischen Weltverschwörung. Frankfurt am Main: Vittorio Klostermann, 2015.

19 En un tono ostensiblemente crítico frente a lo implicado en interpretaciones tales como la heideggeriana, fue expresado que "en nuestro tiempo la polis ya no existe más, y tendría consecuencias desastrosas darle vida nueva a esta noción antigua. Bajo las condiciones de la modernidad, se torna más y más necesario diferenciar entre 'lo político' y 'la política'.» VOLLRATH, E.: "The 'Rational' and the 'Political': An Essay in the Semantics of Politics", p. 24.

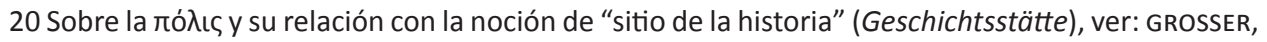
F.: Revolution denken. Heidegger und das Politische 1919-1969, pp. 30, 64, 113-115.

21 HEIDEgGeR, M.: Erläuterungen zu Hölderlins Dichtung, (Friedrich von Hermann ed.), Gesamtausgabe, Band 4. Frankfurt am Main: Vittorio Klostermann, 1981, p. 88.

$22 \mathrm{Me}$ valgo de esta frase acuñada en un contexto diferente, concerniente al análisis de las posiciones de Martin Heidegger en los años '30. Sobre las implicaciones de la condena de la "normalidad de la vida normal" (Normalität des normalen Lebens), ver: fRANZEN, W.: "Die Sehnsucht nach Härte und Schwere. Über ein zum NS-Engagement disponierendes Motiv in Heideggers Vorlesung "Die Grundbegriffe der Metaphysik" von 1929/1930", en Gethmann-Siefert, A. y PÖGGELER, O.: Heidegger und die praktische Philosophie,. Frankfurt am Main: Suhrkamp Verlag, 1989, pp. 78-92.

23 PöGgeler, O.: Der Denkweg Martin Heideggers. Pfullingen: Neske Verlag, 1963, p. 224. 


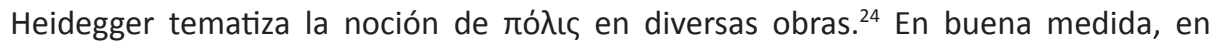

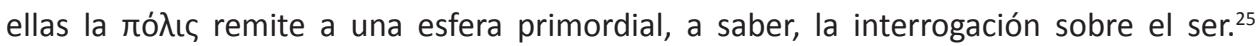
Esta tonalidad radical es evidente, por caso, en la Einführung in die Metaphysik, donde

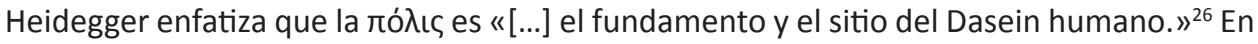
escritos posteriores, tales como Hölderlin's Hymne 'Der Ister', Heidegger sostiene que la

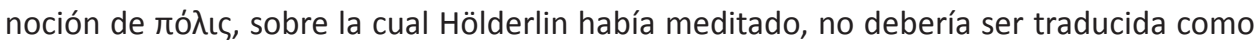
Estado (Staat) o ciudad estado (Stadtstaat) porque, en un sentido básico, implica el sitio de la historia. Es bajo esta égida que Heidegger plantea que "lo político" resulta derivado

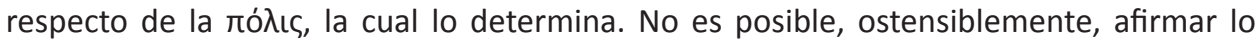

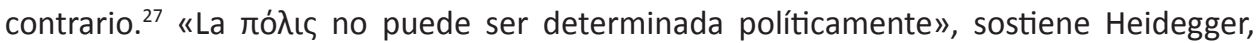

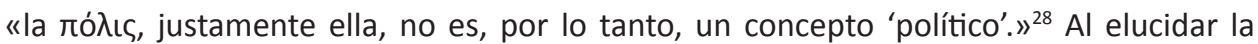

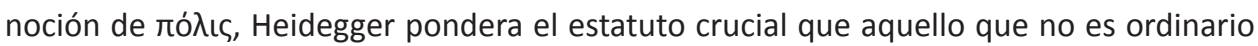

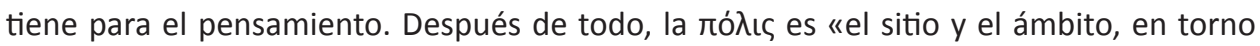

24 Ver: HeIdeggeR, M.: Vom Wesen der Wahrheit: Zu Platons Höhlengleichnis und Theätet, (Hermann Mörchen ed.), Gesamtausgabe, Band 34. Frankfurt am Main: Vittorio Klostermann, 1988; Seminare. Hegel-Schelling, (Peter Trawny ed.), Gesamtausgabe, Band 86. Frankfurt am Main: Vittorio Klostermann, 2011, pp. 59-184; Einführung in die Metaphysik, (Petra Jaeger ed.), Gesamtausgabe, Band 40. Frankfurt am Main: Vittorio Klostermann, 1983; Hölderlins Hymne 'Der Ister', (Walter Biemel ed.), Gesamtausgabe, Band 53. Frankfurt am Main: Vittorio Klostermann, 1984; Parmenides, (Manfred Frings ed.), Gesamtausgabe, Band 54. Frankfurt am Main: Vittorio Klostermann, 1982; "Über Wesen und Begriff von Natur, Geschichte und Staat. Übung aus dem Wintersemester 1933/34", en DENKER, A. y ZABOROWSKI, H.: Heidegger und der Nationalsozialismus. Dokumente, Freiburg/München, Karl Alber, 2009, pp. 53-88.

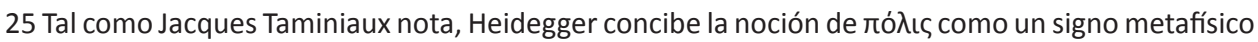
enlazado a la develación del ser. Ver: TAMINIAUX, J.: “Plato's Legacy in Heidegger's Two Readings of Antigone", en Partenie, C. y Rockmore, T.: Heidegger and Plato: Toward Dialogue. Evanston, Illinois: Northwestern University Press, 2005, pp. 35, 41.

26 HEIDEgGeR, M.: Einführung in die Metaphysik, p. 117. Prestando atención a estas aseveraciones, Lacoue-Labarthe sugirió que: «en respuesta al nacionalsocialismo - lo cual obviamente implica una responsabilidad- [Heidegger] buscó pensar una archi-política: polis, dice en 1935, no refiere a 'política' alguna, una palabra que siempre usa entre comillas; polis significa el Da del Sein.» LacoueLabarthe, P.: Heidegger. La politique du poème. París: Éditions Galilée, 2002, p. 161. Ver, también: Aoun, M.: La polis heideggerienne. Lieu de réconciliation de l'être et du politique. Altenberge: Oros Verlag, 1996; Rossi, L.: "La política en su sentido más alto: Los supuestos políticos y metodológicos de la interpretación heideggeriana de Hölderlin" en Revista Latinoamericana de Filosofía XXX, no 1, otoño, 2004, pp. 97-124; Trawny, P.: Sokrates oder die Geburt der politischen Philosophie. Würzburg: Königshausen \& Neumann, 2007; Adyton. Heideggers esoterische Philosophie. Berlín: Matthes \& Seitz, 2010; y Jollivet, S.: "Enjeux de la polémologie heideggerienne: entre Kriegsideologie et refondation politique" en Astérion, L'ami et l'ennemi 6, 2009.

27 Ver adicionalmente: TRAWNY, P.: Heidegger und Hölderlin oder Der Europäische Morgen. Würzburg: Königshausen \& Neumann, 2004, pp. 225-237.

28 HEIDEGGER, M.: Hölderlins Hymne 'Der Ister', p. 99. 
del cual gira todo lo digno de ser preguntado en un sentido extraordinario. ${ }^{29}$ Mediante este tipo de aclaraciones, Heidegger cuestiona una conciencia moderna que, a su criterio, entroniza "lo político" y, por lo tanto, lo torna incondicional, eliminando toda posibilidad de interrogación. "Lo político", de acuerdo a Heidegger, adquiere la naturaleza de una totalidad, es decir, sucumbe ante las certidumbres técnicas e historiográficas y, en esa medida, excluye la posibilidad de todo cuestionamiento. ${ }^{30}$ Es esta torsión del pensamiento heideggeriano, aquello que las teorías contemporáneas que elogian "lo político" simplemente desconocen.

Tales perspectivas, es necesario enfatizar, ocluyen a la vez diversos motivos y repercusiones teóricas de la filosofía de Heidegger. Entre otros, no perciben el estatuto de la noción de "indiferencia modal" (modale Indifferenz) mencionada en los §12 y §45 de Sein und Zeit ${ }^{31}$, omiten la elucidación de la cuestión del ser como una formulación ternaria ${ }^{32}$, y, más esencialmente, desatienden la propia posición de Heidegger respecto de la "diferencia ontológica". En este sentido, fue Hans-Georg Gadamer quien señaló que, frente a cuestiones tales como «qué es efectivamente la 'diferencia ontológica'» o «cómo puede establecerse tal distinción», Heidegger respondía: "Nosotros no hacemos la diferencia. [...] La diferencia es aquello donde entramos. ${ }^{33}$ Bajo esta luz, Gadamer explica que Heidegger conocía los límites de la "diferencia ontológica” y, por lo tanto, más tarde

29 HEIDEGGER, M.: Hölderlins Hymne 'Der Ister', p. 100.

30 De hecho, de acuerdo a Heidegger, «ningún concepto moderno de 'lo político' basta para

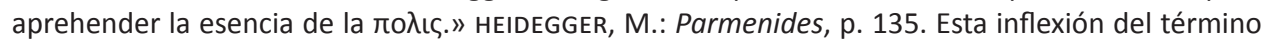
"Io político" es minusvalorada en interpretaciones parciales tales como: FAYE, E.: Heidegger, l'introduction du nazisme dans la philosophie. Precisamente respecto del estatuto del cuestionar, Theodore Kisiel sugiere que la investigación de Heidegger "se remonta fundamentalmente a experiencias interrogativas: angustia, preocupación, culpa, muerte, finitud, nada. La esencia del hombre [reside en] la pasión por interrogar; el sitio donde habita el hombre es el de la aporía de la existencia. El lugar de la verdad es desplazado desde la aseveración hacia la interrogación». KISIEL, T.: "Towards the Topology of Dasein", en SheEHAN, T.: Heidegger. The Man and the Thinker. New Brunswick: Transaction Publishers, 2010, p. 100.

31 Véase, en especial: Dostal, R.: "The Problem of 'Indifferenz' in Sein und Zeit" en Philosophy and Phenomenological Research 43, №. 1, 1982, pp. 43-58. Ver también: RossI, L.: "Ser y tiempo y la fenomenología de la comunidad y la sociedad", en ROCHA, A.: Heidegger hoy: estudios y perspectivas. Sociedad Iberoamericana de Estudios Heideggerianos / Universidad de San Buenaventura: Editorial Grama, 2011, pp. 327-346.

32 Para ahondar en esta cuestión, ver: MARION, J.: Réduction et donation. Recherches sur Husserl, Heidegger et la phénoménologie. París: P.U.F., 1989.

33 Gadamer, H.: "Der eine Weg Martin Heideggers", en Neure Philosophie I. Hegel, Husserl, Heidegger, en Gesammelte Werke, Band III. Tübingen: J. C. B. Mohr (Paul Siebeck), 1987, pp. 423. 
procuró abandonar el término. ${ }^{34}$ Las omisiones mencionadas, sin embargo, apuntan a un olvido adicional sobre el que ya he dado cuenta. Quienes contemporáneamente entronizan la "diferencia política", simplemente pasan por alto la impugnación heideggeriana de "lo político" y asumen que la ontología implica un modo de institución de lo social. Pero esta operación desconoce que, de acuerdo a Heidegger, es la ró

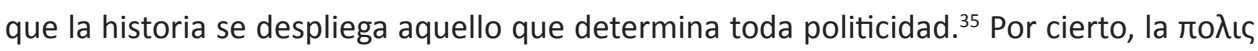
heideggeriana no está vinculada a un dominio empírico estable, sino a la oposición radical entre el ser y la nada. Bajo la interpretación de Heidegger, pues, «la по入ıৎ es en sí el lugar completo del develamiento del ente. ${ }^{36}$

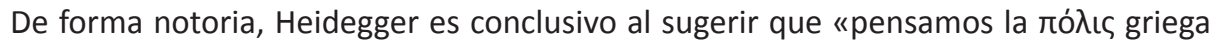
y lo 'político' de modo completamente no-griego. Pensamos lo 'político' de manera

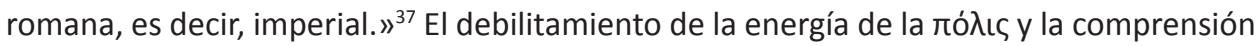
moderna de "lo político" en clave romana, constituyen dos caras de una misma moneda. Y es precisamente por ello que, para utilizar la expresión acuñada por Philippe LacoueLabarthe, Heidegger despliega una "activa deconstrucción de lo político.» ${ }^{38}$ Ahora bien, como es sabido, Schmitt fue el autor que más exhaustivamente teorizó sobre la noción de "lo político" en el contexto de la Alemania de entreguerras. Si bien esta breve exposición no puede dar cuenta acabada de la mésentente entre los autores ${ }^{39}$, es importante

34 Sobre este tema, véase: DAHLSTROM, D. The Heidegger Dictionary. London: Bloomsbury, 2013, p. 147.

35 Tal como sugiere Pöggeler, «la по $\lambda ı \varsigma$ es la morada de la verdad que se reconoce a sí misma.» Pöggeler, O.: Der Denkweg Martin Heideggers, p. 224. Ver también: Pöggeler, O.: Philosophie und Politik bei Heidegger, pp. 27-28.

36 HEIDEGGER, M.: Parmenides, p. 133.

37 HEIDEgGER, M.: Parmenides, p. 63.

38 heidegger, M.: Parmenides, p. 63. Véase: lacoue-labarthe, P. y nancy, J. (ed.): Les fins de I'homme. À partir du travail de Jacques Derrida. París: Editions Galilée, 1981, pp. 415-445. Ver también: FRASER, N.: "The French Derrideans: Politicizing Deconstruction or Deconstructing the Political?" en New German Critique 33, Autumn, 1984, pp. 127-154.

39 Las repercusiones teóricas del desacuerdo entre Heidegger y Schmitt han sido sólo parcialmente analizadas. En general, los estudios ponen atención en dos cuestiones. Por un lado, se menciona la impugnación de los autores al armonicismo racionalista. La ya mencionada carta que Heidegger le envió a Schmitt el 22 de agosto de 1933, en la cual introduce la noción de $\pi 0 \lambda \varepsilon \mu \circ \varsigma$, daría cuenta de la actitud controversial que sus obras patentizan. Por otro lado, y gracias a las problemáticas interpretaciones provistas por Karl Löwith y Christian Graf von Krockow, se acepta comúnmente que el "decisionismo" es el sesgo teórico compartido por Heidegger y Schmitt. LöWITH, K.: Heidegger: Denker in Dürftiger Zeit; vON KROCKOW, C.: Die Entscheidung: Eine Untersuchung über Ernst Jünger, Carl Schmitt, Martin Heidegger. En estas interpretaciones, la decisión emerge como aquello que quiebra la mera repetición de lo establecido. Ver, a la vez: TUGENDHAT, E.: Der Wahrheitsbegriff bei Husserl und Heidegger. Berlín: De Gruyter Verlag, 1967; SITTER, B.: "Zur Möglichkeit dezisionistischer Auslegung von Heideggers ersten Schriften" en Zeitschrift für philosophische Forschung XXIV, № 4, 
revisitarla para así evitar el "uso" inexaminado del pensamiento heideggeriano con el objeto de animar la "diferencia política". En particular, la divergencia entre Heidegger y Schmitt resulta una confrontación acerca de aquello donde reposa "lo extraordinario". Una disputa, vale aclarar, sobre el estatuto de "lo político".

Esta querella intelectual es evidente en el curso que Heidegger impartió en el semestre de invierno de 1933-1934 "Über Wesen und Begriff von Natur, Geschichte und Staat". ${ }^{40}$ Allí, se torna visible un nuevo interés por cuestiones políticas que redunda en el intento por definir la esencia de "Io político" en un sentido ontológico. En este contexto, la relación entre el pueblo y el Estado se presenta emparentada a la relación entre el ente y el ser. Al emprender esta tematización, Heidegger impugna una comprensión de

1970, pp. 516-535; HABERMAS, J.: “Martin Heidegger”, en Philosophisch-politische Profile, pp. 81-82; MARCUSE, H.: "Heidegger's Politics: An Interview"; Harries, K.: "Heidegger as a Political Thinker", p. 310; WEIL, É.: "Le cas Heidegger", en Philosophie et réalité II. París: Beauchesne Éditeur, 1982, pp. 255-266; SCHüRmAnN, R.: Le principe d'anarchie. Heidegger et la question de l'agir, p. 295; y BOHRER, K.: Der Ernstfall Heidegger. Basel: Schwabe \& Co Verlag, 1998. Algunos de estos estudios asocian un carácter decisionista percibido en Sein und Zeit con el pensamiento político de Schmitt. Sugestivamente, sin embargo, tanto Beat Sitter como Karsten Harries observan que, para Heidegger, el fundamento de la decisión no remite a una intuición incuestionada e injustificada. De hecho, el decisionismo pertenece al ámbito de la impropiedad (Uneigentlichkeit). Ver: SITTER, B.: "Zur Möglichkeit dezisionistischer Auslegung von Heideggers ersten Schriften", p. 532; y HARRIES, K.: "Heidegger as a Political Thinker", p. 310. Merece ser mencionado que algunos autores han planteado que la noción de decisión (Entscheideung) schmittiana tampoco debe entenderse como el producto de la mera arbitrariedad e intuición. Ver, por caso: DOTTI, J.: Carl Schmitt en Argentina. Rosario: Homo Sapiens Ediciones, 2000, pp. 863-913; DotTI, J.: "Conversaciones 2", El Río Sin Orillas 1, № 1, Buenos Aires, 2007, pp. 236-267. Más recientemente, el rol del anti-liberalismo se ha consignado como el suelo común entre los pensamiento de Heidegger y Schmitt. Ver, entre otros: RADLOFF, B.: Heidegger and the Question of National Socialism. Disclosure and Gestalt; HEINZ, M.: "Volk und Führer. Untersuchungen zu Heideggers Seminar Über Wesen und Begriff von Natur, Geschichte und Staat (1933/34)", en DENKER A. y ZABOROWSKI H.: Heidegger und der Nationalsozialismus II. Interpretationen, Freiburg/München, Karl Alber, 2009, pp. 55-75; ZABOROWSKI, H.: Eine Frage von Irre und Schuld? Martin Heidegger und der Nationalsozialismus. Frankfurt am Main: Fischer Taschenbuch Verlag, 2010; ROSSI, L.: "Ser y tiempo y la fenomenología de la comunidad y la sociedad"; NORRIS, A.: "Jean-Luc Nancy on the political after Heidegger and Schmitt" en Philosophy and Social Criticism 7, № 8, 2011, pp. 899-913. Aún así, otros análisis enfatizan que existe un desacuerdo teórico profundo entre los autores basado en sus distintas aproximaciones teóricas, es decir, la teoría política y la jurisprudencia, en un caso; la filosofía, en el otro. Sucintamente, mientras que Schmitt analizó problemas políticos de modo detallado durante las décadas del ' 20 y' 30 , este tipo de reflexiones, se sugiere, brillan por su ausencia en el pensamiento heideggeriano de la época. El presente ensayo, sin embargo, busca mostrar que el desacuerdo entre los autores no está meramente basado en cuestiones disciplinarias. Me dedico a estos tópicos en "Ontological Enmity: Martin Heidegger, Carl Schmitt, and the Confrontation on the Political" en: VEGA, F., Extraordinary Matters: Politics and Lifein-Common after Martin Heidegger, (en prensa).

40 heIDEgGeR, M.: "Über Wesen und Begriff von Natur, Geschichte und Staat. Übung aus dem Wintersemester 1933/34", pp. 53-88. 
"lo político" fundada en la oposición entre amigo y enemigo, tal como la concebida por Schmitt. ${ }^{41}$ Estudiosos de la obra heideggeriana agregan que si bien el pensador no se refirió extensamente al Jurist en este caso, intentó lidiar con sus ideas acerca de la soberanía, a tal punto que uno puede encontrar en el mencionado seminario una «intensa polémica de Heidegger con la Teología política de Schmitt. ${ }^{42}$ Más aún, la tematización que Heidegger hace de la oposición entre amigo y enemigo en seminarios subsecuentes tales como "Hegel, über den Staat", implicaría también una crítica al pensamiento de Schmitt y lo que es considerado una totalización de la política. ${ }^{43}$

Las tematizaciones de Heidegger sobre "lo político", en definitiva, adquirirán un carácter decididamente negativo luego de su período como rector de la Albert-LudwigsUniversität Freiburg. Esta nueva inflexión, sin embargo, mantiene una actitud crítica hacia lo expuesto por Schmitt. Como ilustración, en Hölderlins Hymnen "Germanien" und "Der Rhein", Heidegger sugiere que la contribución a que la poesía de Hölderlin devenga poder histórico para el pueblo alemán, «es 'política' en el sentido más alto y más propio, tanto que, quien lleve algo a cabo en este sentido, no tiene necesidad de discurrir sobre lo 'político'. $»^{44}$ En trabajos tales como Parmenides y, nuevamente, sin mencionar al Jurist por su nombre, Heidegger afirma que la comprensión schmittiana de "lo político" no consigue

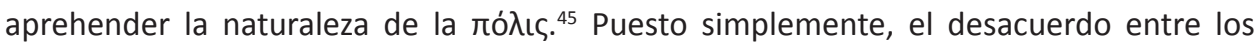
autores está basado en una orientación particular de sus pensamientos: mientras que la obra de Heidegger expresa una fascinación por Grecia ${ }^{46}$, la de Schmitt muestra una extrema admiración por la forma política romana.

41 Para ahondar en esta interpretación, ver: тномё, D.: "Heidegger und der Nationalsozialismus. In der Dunkelkammer der Seinsgeschichte", en тномё, D.: Heidegger Handbuch. Leben-Werk-Wirkung. Stuttgart-Weimar: J. B. Metzler Verlag, 2003, pp. 150; MEHRING, R.: "Heidegger und Carl Schmitt. Verschärfer und Neutralisierer des Nationalsozialismus", en THOMÄ, D.: Heidegger Handbuch. LebenWerk-Wirkung, Stuttgart-Weimar, Verlag J. B. Metzler Verlag, 2003, pp. 343; "Der philosophische Führer und der Kronjurist: praktisches Denken und geschichtliche Tat von Martin Heidegger und Carl Schmitt" en Deutsche Vierteljahresschrift für Literatur und Geistesgeschichte 68, 1994, pp. 333-363.

42 ZABOROWSKI, H.: Eine Frage von Irre und Schuld? Martin Heidegger und der Nationalsozialismus, pp. 420-421. Ver también: FISTETTI, F.: Heidegger e I'utopia della polis. Genova: Casa Editrice Marietti, 1999.

43 Ver: HEIDEGGER, M: Seminare. Hegel-Schelling, pp. 59-184.

44 HeIdegger, M.: Hölderlins Hymnen 'Germanien' und 'Der Rhein', (Susanne Ziegler ed.), Gesamtausgabe, Band 39. Frankfurt am Main: Vittorio Klostermann, 1989, p. 214. (Énfasis agregado).

45 Ver, por caso: RADLOFF, B.: Heidegger and the Question of National Socialism. Disclosure and Gestalt, p. 256. Ver también: ELDEN, S.: "Rethinking the Polis Implications of Heidegger's questioning the political" en Political Geography 19, 2009, pp. 407-422.

46 Ver, entre otros: GILLESPIE, M.: "Martin Heidegger", en STRAUSS, L. y CROPSEY, J.: History of Political Philosophy. Chicago: University of Chicago Press, 1987, p. 900; EscouBAS, E.: "Heidegger, la question romaine, la question impériale: Autour du 'Tournant', en ESCOUBAS, E.: Heidegger: 
Pero, recapitulemos: en un tono lindante al "excepcionalismo", la $\pi$ ? $\lambda \iota \varsigma$ se yergue allende "lo político". Y, aún así, incluso cuando Heidegger parece sucumbir ante la "fascinación por lo extraordinario"; su palabra da a ver un camino diferente, buscando evitar la deriva "excepcionalista". ${ }^{47}$ "Lo des-comunal es lo simple, insignificante», sugiere Heidegger. Y prosigue, «lo asombroso es para los griegos lo simple, insignificante, el propio ser. [...] Lo así entendido como des-comunal no es, en relación con lo familiar, la excepción, sino lo 'más

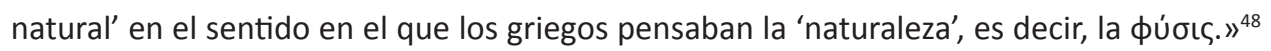
Como resulta perspicuo, Heidegger intenta impugnar la tentación "excepcionalista". "Lo extraordinario", entonces, habita "lo ordinario" y viceversa. ${ }^{49}$ Ante este atolladero, sin embargo, la posición de Heidegger muestra una ambivalencia irreductible que penetra su confrontación con todo exceso..$^{50}$ Por ello es necesario interrogar: ¿ pudo Heidegger limitar su "fascinación por lo extraordinario"? ¿No debemos extraer lecciones de su errancia?

Questions ouvertes. Paris: Osiris, 1988, pp. 173-88; FISTETTI, F.: Heidegger e l'utopia della polis, pp. 25-37; volPI, F.: "Heidegger et la romanité philosophique" en Revue de métaphysique et de morale 31, 2001/3, pp. 287-300; SPANOS, W.: “Heidegger's Parmenides: Greek Modernity and the Classical Legacy" en Journal of Modern Greek Studies 19, № 1, mayo, 2001, pp. 89-115; y RossI, L.: "La política en su sentido más alto: Los supuestos políticos y metodológicos de la interpretación heideggeriana de Hölderlin", pp. 120-123; ROSSI, L.: "Hölderlin como clave secreta de la nación alemana", en RochA, A.: En torno a Heidegger. Barranquilla: Ediciones UniNorte, 2008, pp. 376377. Respecto de la fascinación de Heidegger por Grecia, Heinrich Petzet planteó que «quien mire los títulos de las lecciones en Marburgo y Friburgo entre 1923 y 1944, podrá tener una idea acerca del significado que el diálogo con los pensadores griegos ha tenido para Heidegger.» PETZET, H.: Auf einem Stern zugehen: Begegnungen und Gespräche mit Martin Heidegger. 1929-1976. Frankfurt am Main: Frankfurter Societäts-Druckerei, 1983, p. 169. Ver también: PöGGELER, O.: Der Denkweg Martin Heideggers, pp. 195-206.

47 Un reconocido estudioso de la obra heideggeriana supo alguna vez afirmar: «Bergson ha escrito que todo gran filósofo medita sobre un único e inextinguible pensamiento y pasa toda su vida tratando de expresarlo: Et c'est pourquoi il a parlé toute sa vie.» SHEEHAN, T.: "Introduction: Heidegger, the Project and the Fulfillment", p. vii. En el caso de Heidegger, ese pensamiento inextinguible resultó un ajuste de cuentas con lo "extraordinario".

48 HeIdegger, M.: Parmenides, pp. 150-151.

49 De acuerdo a Theodore Kisiel, incluso el Dasein, una de las nociones centrales dentro del pensamiento heideggeriano, «expresa la alucinante simplicidad de la situación humana, articulándose en una gama de revelaciones que van desde lo más rutinario y común (commonplace) hasta el extraordinario (extraordinary) y poco común (uncommon) choque de auto-reconocimiento en el cual uno es tomado por sorpresa por todo lo que significa estar aquí.» KISIEL, T.: "Towards the Topology of Dasein", p. 97. (Énfasis en el original). Una inflexión similar es ostensible en un pasaje de la obra de Heidegger crucial respecto de lo que en este texto se propone. Téngase a bien, entonces, ver: HeIDEgGeR, M.: Parmenides, p. 156. A la vez, conviene recordar, Heidegger sugiere que «experimentar lo más próximo es lo más dificultoso.» Heidegger, M.: Parmenides, p. 201.

50 La noción de "ambivalencia" debe mucho a Le change Heidegger. Du Fantastique en Philosophie. En esta obra, Catherine Malabou estudia la presencia de cambios (Wandeln), transformaciones (Wandlungen), y metamorfosis (Verwandlungen) en la letra heideggeriana. MALABOU, C.: Le Change Heidegger. Du Fantastique en Philosophie. París: Éditions Léo Scheer, 2004. 
¿Existen modos de aproximarse a lo inefable? ¿No fue precisamente Heidegger uno de los pensadores que buscó mostrar la inefabilidad de lo inefable? Tal inefabilidad, por cierto, resuena en sus asunciones respecto de la noción de $\pi$ o $\lambda$ ı y en su afrenta respecto del "elogio de lo político". Es precisamente esta consideración teórica la que brilla por su ausencia en las filosofías contemporáneas que, al invocar el "recentramiento de lo político", anulan el misterio que anida en la vida en común. ${ }^{51}$

La repetición del apotegma que señala que lo-político-es-siempre-ya-la-exaltación-delconflicto-y-de-la-contingencia, pues, aparece como un mantra que, de modo paradójico, debilita el arcano de la política: sic transit gloria mundi. Difícilmente, como se ha mostrado, Heidegger pueda resultar un precursor de este tipo de maniobra y las certidumbres que trae aparejada. La vida en común, quizás por fortuna, hace que el arcano de la política no sea una materia inexpugnable a la espera de ser desentrañada, sino un lazo que se muestra en la superficie de las cosas: la política supone la co-pertenencia de momentos "ordinarios" y "extraordinarios", remisos a su aprehensión por el binarismo presente en la distinción entre "la política" y "lo político". Reiner Schürmann, uno de los más originales intérpretes de la filosofía heideggeriana, fue consciente de la trampa "excepcionalista" y del entrelazamiento en distinta dirección que esta intervención busca poner a la luz. Por ello, bajo la influencia del pensamiento de Heidegger, sugirió que la ficción de un fundamento estabilizador último no puede sostener lo común, que se ve atravesado por la plurificación del principio. ${ }^{52}$ Probablemente Heidegger no alcanzó a expresar este matiz, que las tendencias que elogian "lo político" sencillamente desconocen.

En suma, es sin dudas cierto que las consideraciones heideggerianas frente al "elogio de lo político" expresan un gesto ambivalente. De hecho, su radicalismo filosófico ${ }^{53}$, su deseo

51 Me dedico con detalle a este asunto en "Can the Common Dwell in an Exceptional Act? The Political Difference and its Discontents" en: VEGA, F., Extraordinary Matters: Politics and Life-inCommon after Martin Heidegger, (en prensa).

52 SCHÜRMANN, R.: Le principe d'anarchie. Heidegger et la question de l'agir; $\mathrm{y}$ “Principles Precarious: On the Origin of the Political in Heidegger", pp. 245-256. Ver, también: TRAWNY, P.: Irrnisfuge. Heideggers An-archie. Berlín: Matthes \& Seitz, 2014.

53 Para ahondar en la noción de radicalismo (Radikalismus) provista por el filósofo, ver: HEIDEGGER, M.: Überlegungen XII-XV (Schwarze Hefte 1939-1941), p. 15. Karl Jaspers percibió este tono del pensamiento heideggeriano al sostener que Heidegger procede «como si combinara la seriedad de un nihilismo con la mistagogia de un mago.» Jaspers en отт, H.: Martin Heidegger. Unterwegs zu seiner Biographie, p. 316. Ver también: DERRIDA, J.: D'un ton apocalyptique adopté naguère en philosophie. Paris: Éditions Galilée, 1983. En este sentido, fue sostenido que: "Heidegger ya no fue para [Jaspers] el modelo de lo que un filósofo podría ser, sino, por el contrario, un antifilósofo demoníaco consumido por fantasías peligrosas.» LILLA, M.: The Reckless Mind. Intellectuals in Politics. New York: The New York Review of Books, 2001, p. 34. Ver, a la vez: HALLWARD, P.: Badiou a Subject to Truth. Minneapolis: University of Minnesota Press, 2003, pp. 20, 22, 216. La impugnación 
de quebrar el imperio de "lo ordinario", su búsqueda de lo grandioso, tuvo como efecto consecutivo la condena de "la normalidad de la vida normal". Sin embargo, la intervención heideggeriana puede ser leída como una invitación que refiere a las capacidades de olvidar y recordar el exceso. El interrogante sobre el modo de instituir la vida en común planteado al inicio de este texto, entonces, adquiere un tono diferente. Su re-comienzo nos lleva a preguntar: ¿qué debemos olvidar y qué debemos recordar para vivir en común una vez que la fe en el fundamento trascendente que solía ordenar los lazos políticos cayó en desgracia? Un examen crítico de la "fascinación por lo extraordinario", por fin, puede ayudarnos a lidiar con el enigma de la vida en común sin sucumbir ante la totalización de "lo político". Sólo podremos intentar salir airosos de este brete filosófico-político si aceptamos que "lo ordinario" y "lo extraordinario" no se anulan entre sí. ${ }^{54} \mathrm{Y}$ es en la reinscripción política de esta torsión donde reposa el enigma:

todo es diferente de como tú piensas, de como yo pienso,

la bandera aún flamea,

los pequeños secretos todavía permanecen,

arrojan todavía sombras, de eso

vives tú, vivo yo, vivimos. ${ }^{55}$

de la idea de considerar a Heidegger como un antifilósofo, aún cuando excede el horizonte mentado por Jaspers, es evidente en: BOSTEELS, B.: "Radical Antiphilosophy" en Filozofski vestnik XXIX, №2, 2008, pp. 155-187, pp. 160, 167-168.

54 Véase, por caso: HAAR, M.: "The Enigma of Everydayness", en SALLIS, J.: Reading Heidegger. Commemorations. Bloomington: Indiana University Press, 1993, pp. 20-28. Me he expresado sobre el asunto en: VEGA, F. et al.: "¿Lo político habita sólo en la excepción?" en Revista Argentina de Ciencia Política 13-14, Buenos Aires, Eudeba, 2011, pp. 187-203.

55 CELAN, P.: Gesammelte Werke in fünf Bänden, (Beda Allemann y Stefan Reichert ed.), Band 1. Frankfurt am Main: Suhrkamp Verlag, 1986, p. 284. 